예인식 심해용 비디오카메라를 이용한 대게의 서식밀도 추정

안희춘' $\cdot$ 이경 훈 ${ }^{*} \cdot$ 배재현 $\cdot$ 배봉성' 신종근

국립수산과학원 수산공학과, ${ }^{1}$ 동해수산연구소 자원환경과, ${ }^{2}$ 국립수산과학원 연구기획과

\title{
Estimation of the distribution density of snow crab, Chionoecetes opilio using a deep-sea underwater camera system attached on a towing sledge
}

\author{
Heui-Chun AN ${ }^{1}$, Kyoung-Hoon LEE*, Jae-Hyun BAE, Bong-Seong BAE ${ }^{1}$ and Jong-Keun SHIN ${ }^{2}$
}

Fisheries Engineering Division, National Fisheries Research \& Development Institute, Busan 619-705, Korea

${ }^{1}$ Fisheries Resources \& Environment Division, East Sea Fisheries Research Institute, NFRDI,

Gangneung 210 - 703, Korea

${ }^{2}$ Research \& Development Planning Division, NFRDI, Busan 619-705, Korea

This study shows that the distribution density of snow crab, Chionoecetes opilio, was estimated using an underwater video monitoring system attached on the towing sledge. The field experiments were carried out at the coastal waters around Chuksan, East Sea, where ranged from 110 to $130 \mathrm{~m}$ depth during September and October 2007. The sledge was towed for 40 minutes and the towing speed was controlled between 1.5 to 1.7 knot and each research areas were calculated to multiply towed distance by the detection width of the video monitoring system $(1.2 \mathrm{~m})$, and then, distribution density of snow crab in each observations were estimated as a counted number of crab per $1,000 \mathrm{~m}^{2}$. The result shows that their survey, taken between two months, reflected similar results during survey period, and the maximum and mean distribution densities in September estimated to be $77.0\left(\right.$ number $\left./ 1,000 \mathrm{~m}^{2}\right)$ and 19.9 , respectively, and those of October were 36.0 and 21.8 , respectively.

Key words : Snow crab, Distribution density, Sledge, Underwater video camera

서 론

우리나라 동해안의 특산품으로 유명한 대게
(Chionoecetes opilio) 는 한국 동해, 오호츠크해, 베 링해, 북태평양 및 북대서 양의 북아메 리카 대

\footnotetext{
*Corresponding author: khlee71@nfrdi.go.kr, Tel:82-51-720-2571, Fax:82-51-720-2586
} 
륙 측에 많이 서식하고 있는 것으로 알려져 있으 며, 우리나라 동해에서는 수심 $100-500 \mathrm{~m}$ 에 주 로 서식하고 있다. 우리나라에서는 연 근해 자망 에 의한 대게 생 산량이 $90 \%$ 이 상을 차지하고 있 으나(NFRDI, 2005), 일 본에 서는 통 발로 어획하 고 있으며 일부는 저인망에 의 해 어획되고 있다. 최근에는 2 천톤 이상의 높은 어획고로 동해안어 업의 대표적인 소득원이 되고 있는 대게에 관한 연 구는 해역별 크기 및 성숙에 관한 생리적인 측 면(Lim et al., 2000, Jadamec et al., 1999)과 자원 관리형어업을 위한 망목선 택성 연 구(Park et al., 2003), 예인식 광학기법을 이옹하여 대게의 서 식 밀도(Watanabe et al., 2001) 추정 그리고 트롤 어 구에 대한 도푀행 동(Fujita et al., 2006) 등 국내 외 적으로 다양한 연 구가 진 행되 어 왔다.

본 연구는 우리나라의 주요 연근해어업에서 사용하고 있는 어구의 어획효율을 구명하기 위 한 선행연구로서, 해저에 분포하고이 동성이 적 은 대게를 대상으로 심해용 카메라가 장착되어 있는 예인식 관찰시스템(Sledge)을 이용하여 서 식하는 해역의 분 포밀 도를 추정하였다.

\section{재료 및 방법}

대게의 서식밀도 조사는 경상북도 축산 - 죽 변 인근해역의 수심 $110-130 \mathrm{~m}$ 되는 어장을 중 심으로 실시하였으며, 주 조업시기(12월 - 익년 4월경)에는 조업해역 에 집중적으로 부설된 자 망어구로 인하여 해상시험이 불가능하였으며, 2007년 9월 과 10 월에 걸쳐 국립수산과학원 동해 수산연구소 탐구5 호(R/V 262G/T) 를 이용하여 해 상시험을 실 시하였다(Fig. 1).

조사예 인체 는 Fig. 1 과 같이 남북 방향으로 설 정된 조사라인에서 $1.5-1.7 \mathrm{knots}$ 를 유지하면서 평균 40 분간 예 인하며 촬영하였다. 추가적으로, 예인체에 의한 해저저 질의 영항을 퐈악하고 조 사해역에 분포하고 있는 대게의 분포밀도 추정 에 대한 조사라인의 공간통계적인 신뢰도를 검 토하기 위하여 예인체를 남북 방향으로 예인한

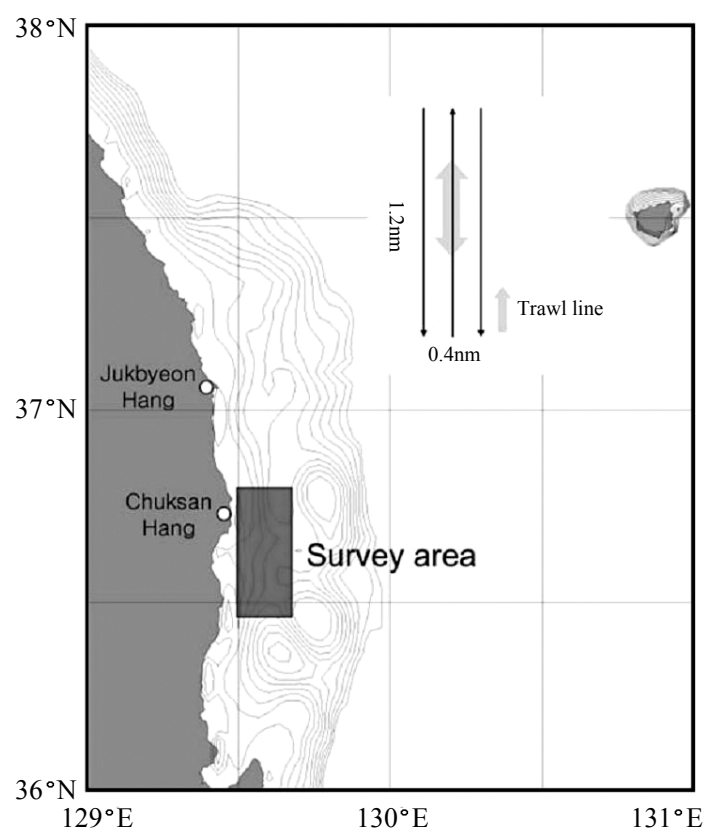

Fig. 1. Survey area in the eastern coastal waters of Korea.

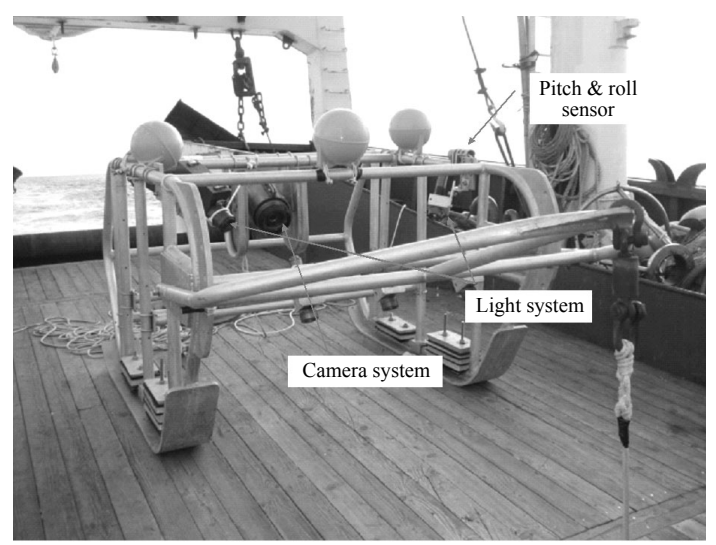

Fig. 2. Photograph of the video monitoring system on a towed sledge.

후 동서 방향으로 예 인하였다.

본 조사에 사용된 예 인식 관찰시 스템 은 Fig. 2 와 같이 알루미 늠 재 질의 썰 매형 예 인체(L192 × $\mathrm{W} 155 \times \mathrm{H} 110 \mathrm{~cm}$, Width of towed plate: $20 \mathrm{~cm}$ ) 에 수 심 $1,000 \mathrm{~m}$ 까지 운용이 가능한 스테인레 스제 내 압 하우징에 각각 수중비디 오카메 라(HDR-HC3, Sony) 와 조명용 광원(High Intensity Discharge 

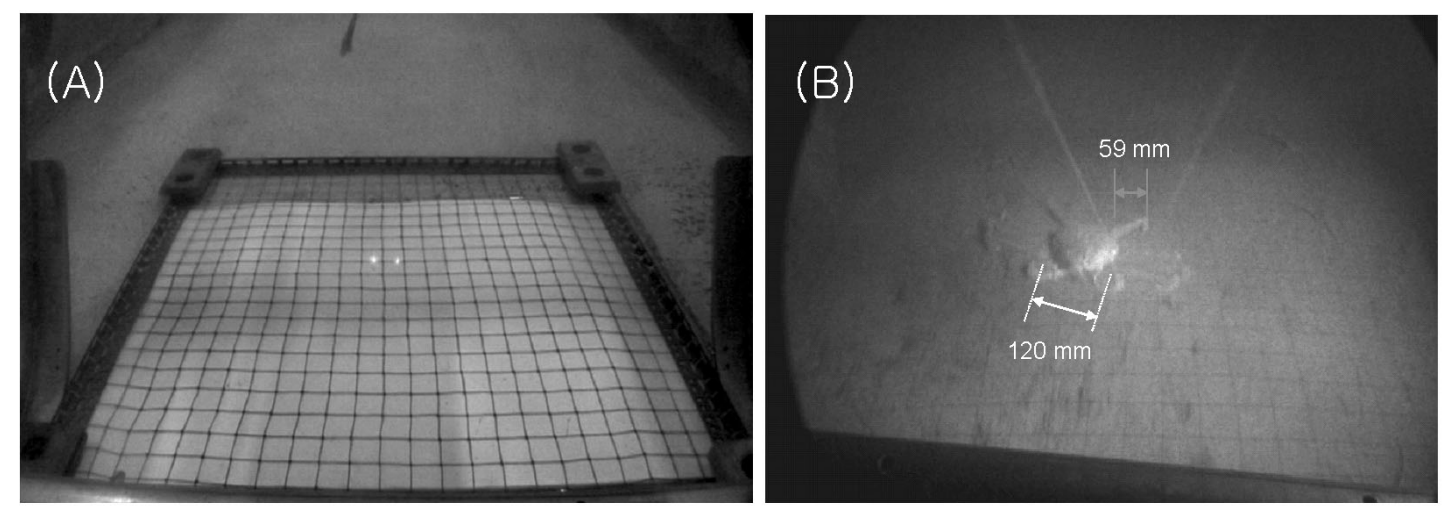

Fig. 3. Calibration picture in seawater tank(in air, A) and Snow crab captured to overlay by underwater video camera(in water, B).

Lamp, DC12V $-35 \mathrm{~W}, 150 \mathrm{~W})$ 을 설치하여 관찰하 였으며, 조사해역에서 최적의 촬영각도를 고려 하여 해 상실험을 완로한 후, 국립수산과학원 수 산공학수조동에 설치되어 있는 해수수조(L500 $\times \mathrm{W} 300 \times \mathrm{H} 150 \mathrm{~cm})$ 에서 Fig. 3(A) 와 같이 공기중 노출된 상태에서 예인체와 일정간격으로 구성 된 교정판을 설치하였다. 이 때, 비디오카메라가 내장되어있는 내압 하우징에 레이 져포인터 $(\mathrm{LP}-5000,3 \mathrm{M})$ 를 일 정간격으로 설치하여 공기 중 및 수중에서의 교정판 규격과 비교하여 탐지 영역범위를 결 정하였으며, 예인체 에 경각센서 (DST pitch\&roll, Star-Oddi) 를 부착하여 시간에 따른 수심, 수온 및 경사각도 등의 정보로부터 예인상태의 안정성 확인 및 예인시간당 영상판 독에서 관찰 가능시간을 기준으로 신뢰구간영 역(q) 을 산출하고, 관찰면 적 $\left(\mathrm{m}^{2}\right.$, 예 인거리 $\times$ 탐지 범위)에 대한 발견미수로 조사해역의 분포밀도 를 추정하였다.

그리고, 조사 초기에 는 예인체 앞쪽에 다이니 마로프 $(\phi 8 \mathrm{~mm})$ 를 수심에 따라 $60-100 \mathrm{~m}$ 연결하 고 조사선 의 트롤 예인용 와이어 로프 $(\phi 20 \mathrm{~mm})$ 에 연결하여 예인하였다. 이 때, 파랑이나 선속의 변화 등의 영향에 의해 발생될 수 있는 예 인체 의 동요를 억제하고, 유실어 망이나 침전 해양쓰레 기 등이 예인체 에 걸려 로프가 퐈단되 거나 안정 성이 저하되는 문제를 해결하기 위하여 일정 간
격으로 부이 $(\phi 250 \mathrm{~mm})$ 를 부착하여 예인하였다. 조사해역의 수심에 따른 예인줄의 길이는 해저 생물을 관찰할 수 있는 시야를 확보하면서 예인 시스템이 해저에 착지된 상태로 안정적으로 예 인될 수 있는 수심별 적정 예인줄 길이를 파악하 기 위하여 일정범위에 센서(DST pitch\& roll, Star-Oddi) 를 부착하였다. 이 결과를 토대로 조사 해역(수심 $110-130 \mathrm{~m})$ 인 경 우 예인줄 길이를 수 심의 약 2 배로 설정하여 일정 선속을 유지하면 서 해저에 분 포하는 대게를 관찰하였다.

\section{결과 및 고찰}

예인식 관찰시스템을 이용하여 총 40 여회에 걸쳐 분포밀 도를 조사하였으나, 끌줄이 해저에 닿거나 투기된 해양쓰레기와 주변 저인망어선 의 조업에 의한 영향으로 해저생물의 탐지가 불 가능하였던 경 우가 빈번하여 자료의 분석에 는 9 월 에 9 회, 10 월 에 8 회 의 자로만을 대 상으로 분석 하였다.

관찰면 적과 출현한 대게의 미수, 대게의 분포 밀 도를 9 월 과 10 월 로 구분하여 각각 Table 1 과 Table 2 에 나타내 었다. 그리고, 이 결 과를 토대로 조사해역의 정 점별 대 게의 분 포밀 도를 Fig. 3 과 같이 나타내 었다.

본 조사에서 예인 면 적은 $1076.3-3586.8 \mathrm{~m}^{2}$ 범 위 였으며, 출현한 대게는 $10-179$ 마리로 나타났 
안희춘 - 이경훈 - 배재헌 · 배봉성 - 신종근

Table 1. Density of snow crab in the survey sites estimated by underwater video monitoring system on a towed sledge in September, 2007

\begin{tabular}{l|c|c|c|c|c|c|c|c|c|c}
\hline \multicolumn{1}{c|}{ September } & Sep_1 & Sep_2 & Sep_3 & Sep_4 & Sep_5 & Sep_6 & Sep_7 & Sep_8 & Sep_9* & Avg. \\
\hline Mean Depth $(\mathrm{m})$ & 123 & 120 & 115 & 122 & 117 & 118 & 119 & 120 & 120 & 119.3 \\
Measured Area $\left(\mathrm{m}^{2}\right)$ & 1507.1 & 1564.7 & 3069.7 & 1753.5 & 2528.7 & 2861.4 & 3586.8 & 1285.6 & 2325.3 & 2275.9 \\
Measured Counts & 13 & 26 & 109 & 35 & 11 & 18 & 12 & 10 & 179 & 45.9 \\
Density(No./1,000m $\left.{ }^{2}\right)$ & 8.6 & 16.6 & 35.5 & 20.0 & 4.3 & 6.3 & 3.3 & 7.8 & 77.0 & 19.9 \\
\hline
\end{tabular}

※ towed in east-west direction(*)

Table 2. Density of snow crab in the survey sites estimated by underwater video monitoring system on a towed sledge in October, 2007

\begin{tabular}{l|c|c|c|c|c|c|c|c|c}
\hline \multicolumn{1}{c|}{ October } & Oct_1 & Oct_2 & Oct_3 & Oct_4 & Oct_5 & Oct_6 & Oct_7 & Oct_8 & Avg. \\
\hline Mean Depth $(\mathrm{m})$ & 114 & 123 & 121 & 122 & 126 & 123 & 124 & 124 & 122.1 \\
Measured Area $\left(\mathrm{m}^{2}\right)$ & 2394.7 & 1076.3 & 1321.0 & 1882.5 & 2417.3 & 1235.3 & 1527.6 & 2047.3 & 1737.7 \\
Measured Counts & 82 & 22 & 10 & 27 & 87 & 38 & 17 & 41 & 40.5 \\
Density(No./1,000m $\left.{ }^{2}\right)$ & 34.2 & 20.4 & 7.6 & 14.3 & 36.0 & 30.8 & 11.1 & 20.0 & 21.8 \\
\hline
\end{tabular}

* towed in east-west direction(*)

다. 조사해역에서 대게의 최대 분포밀 도는 9월 의 경 우 울진 주변연안에서 77.0(number/ $\left.1,000 \mathrm{~m}^{2}\right)$ 을 나타내었고, 평균 분포밀도는 19.9 (number $\left./ 1,000 \mathrm{~m}^{2}\right)$ 로 추정되었으며, 10 월 의 경우 최대 분포밀 도는 축산항 남쪽연 안에서 36.0 (number $\left./ 1,000 \mathrm{~m}^{2}\right)$ 로 나타났으며, 평 균 분포밀 도 는 21.8(number $\left./ 1,000 \mathrm{~m}^{2}\right)$ 로 추정되 었다. 조사해 역에서의 대게의 서식밀 도는 조사 정점에 따라 차이가 큰 것으로 나타났으나, 9 월 과 10 월 의 평 균 분 포밀 도는 큰 차이를 보이지 않았다.

또한, 대게의 공간적 인 분포해역에 대한 조사 라인의 신뢰영역을 검토하기 위하여 남북방향 과 동서방향의 분포결 과를 비고한 결과, 9 월에 는 남북방항(7.8)보다 동서방항(77.0)이 약 10 배 가량 높은 밀 도분 포를 나타내었으며, 10 월 에는 약 2 배가량 동서방향이 높게 나타났다. 본 연구 방법과 동일한 예인식 수중카메라기법에 의한 일본 Oki 섬 인근해역 에서 조사한 결과 (Watanabe et al, 2001)에서도 대게의 분포밀 도를 1 - 10(number $\left./ 1,000 \mathrm{~m}^{2}\right)$ 으로 보고하고 있는데, 이 러한 원인으로 조사해역의 서식수심 과 자원의 풍도에 따라 차이가 있으며 모니터링조사대상 인 대게의 경우 분포밀도를 추정하는 방법으로 예인식 수중카메라기법은 유용하다는 것으로 판단된다. 또한, 해저면 에 서식하는 대게의 분 포
형태는 일정수심에 대해서도 불규칙적인 분포 를 나타내고 있으므로 이동성이 적 은 대 게를 대 상으로 하는 분 포밀 도조사에서는 생태지리적인 접근방법 과 신뢰도 높은 조사라인 의 공간통계 적 접근방법을 고려한 조사방법의 검토가 필요 한 것으로 사료된 다.

본 조사해역의 저층 생태계 환경은 부드러운 뻘로 형성되어 있었으며, 거미 불가사리 (Ophioplocus japonicus) 와 해 조류, 새 우류 등이 다수 출현하였으며 넙치류와 같은 어류도 확인 되었다. 저장된 동영상을 이용한 영 상 판독에서 는 예인체 의 접근(자극)에 대한 대게의 행 동반 응이 빈번하지 않은 것으로 보아, 그다지 민감한 움직임은 보이지 않았으며, 조사선의 예인속도 를 $1.5 \mathrm{knots}$ 보다 낮게 할 경우 조종성 능이 저하 되어 바람에 의해 조사선 박이 밀리는 현상이 자 주 발생하여 저속으로 안정적인 예인이 어려웠 으며, 예인속도가 $2.0 \mathrm{knots}$ 보다 빠른 경 우에는 정지화상의 분해능이 낮아, 출현한 대게의 암수 구별이 어려웠다. 따라서, 본 조사에서는 최적의 실험조건을 고려할 때, 적절한 선속을 유지하면 서 탐지영역의 조명각도 및 촬영영상에 대한 고 분해능 영상처리기법의 보완으로 해결할 수 있 을 것으로 판단된 다.

본 조사에서 총 40 여회에 걸쳐 예 인체 로 조사 


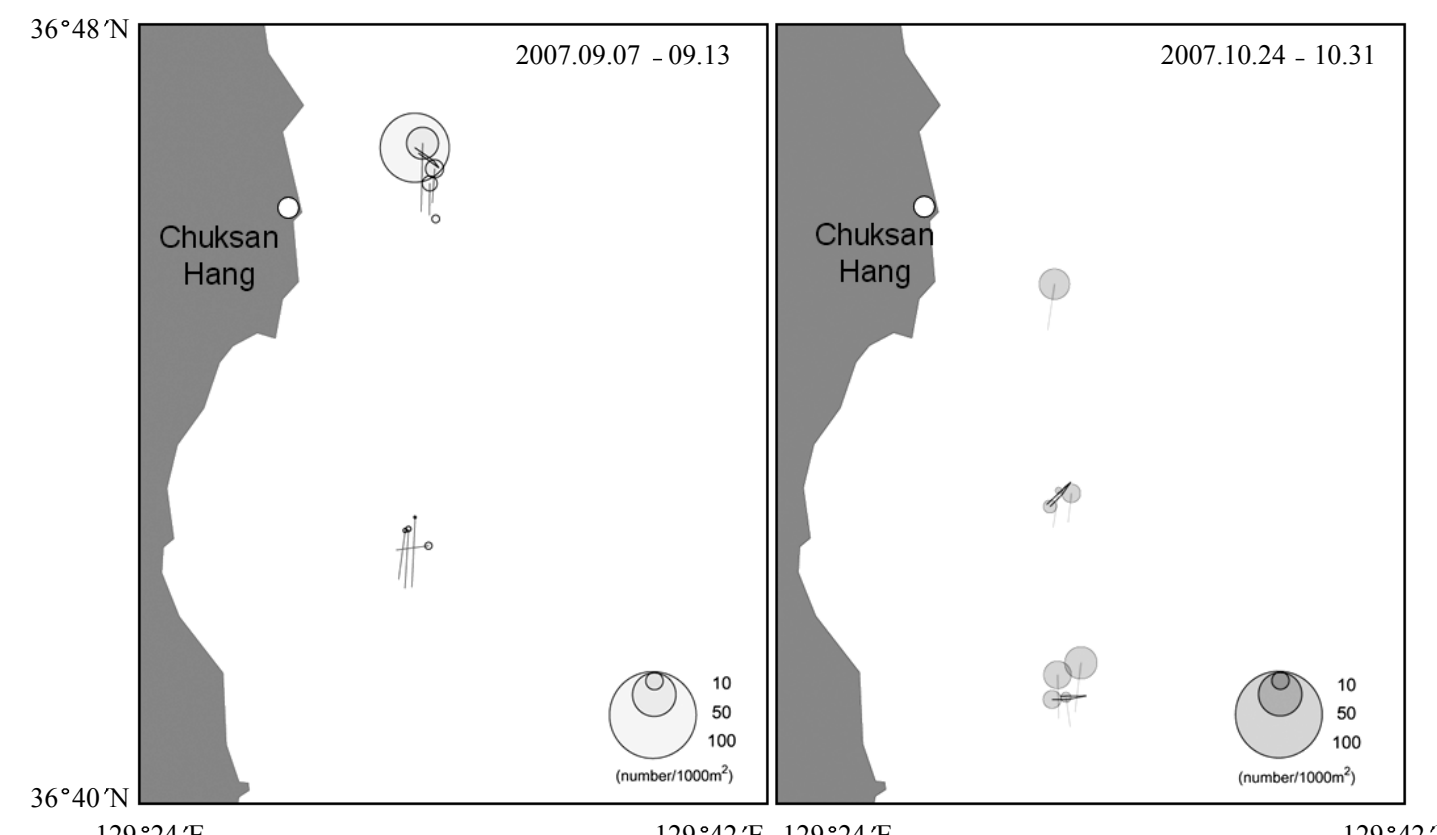

Fig. 4. Distributed density of Snow Crab in the survey sites using the optical methods during September(A) and October(B). Circle indicates the number of Snow Crab in 1,000 square meter.

를 하였으나, 유실된 자망이나 통발 등의 어구가 예인체에 걸려서 분진이 대 량 발생하는 영향으 로 인하여 예인과정에서의 저장된 동영상의 판 독이 어려운 경 우가 빈번히 발생하여, 총 조사회 수에 비해 비교적 낮은 확률의 저장자료(17회) 의 분석만 가능하였다. 이 와 같이 광학기법에 의 한 예인시스템은 조사기간 대비 효율성은 비교 적 낮은 측면은 사실이지만, 자원조사용 예 인어 구에 의한 밀 도조사에 비해 해저생태계에 대한 친환경적인 조사기법이다. 또한, 조사 시기 및 해역의 통계학적 조사라인을 고려하여 서식밀 도를 추정하여 자망·통발과 같은 정치성 어구 의 어획호율을 산정하는 중요한 조사기법으로 발전이 가능하며, 향후 대게 자원의 지속적인 관 리를 위해서도 조업어 장의 유실 어 구에 대한 모 니터링을 통해 조업어장의 환경개선작업에 중 요한 정보를 제 공할 수 있을 것으로 판단된다.

\section{결 론}

본 연구는 동해안 어업의 주요어종인 대게를 대 상으로 2007년 9-10월 에 자망어업의 주요어 장인 동해안 축산항 인근해 역에 수중비 디오카 메라가 부착되어 있는 예인시스템을 이용하여 서식밀 도를 추정하였다. 조사해역은 수심은 $110-130 \mathrm{~m}$ 였으며, 예인속도는 $1.5-1.7 \mathrm{knots}$ 로 약 40 분정도 해저에 분포하는 대게를 관찰하였 다. 또한 카메라의 탐지범 위와 예인거리를 고려 하여 조사면적당 대게의 출현비로 밀도를 추정 하였다. 그 결과, 조사 기간동안 서식해역에 분 포하는 대게 의 평균 분포밀도는 각각 $19.9 \mathrm{number} / 1,000 \mathrm{~m}^{2}$ 및 약 $21.8 \mathrm{number} / 1,000 \mathrm{~m}^{2}$ 로 서, 9,10 월에 큰 차이를 나타내지 않았으나, 최 대 분포밀 도에서는 9 월 에 조사한 해역이 약 2 배 가량 높게 출현되었다. 향후 추가적인 실험을 통 해 조사 기간및 수심별 동해안 대게의 분포밀도 추정이 가능할 것으로 판단된 다. 
사 사

본 연구는 국립수산과학원(수산자원회 복을 위한 어업별 어획 성능 정량화 연구, RP - 2008 $\mathrm{FE}-005)$ 의 지원 에 의해 수행 되었으며, 본 조사 가 원활하게 진행될 수 있도록 적극적으로 협조 하여 주신 국립 수산과학원 조사선 탐구5호 이재 길 선장님을 비롯한 선박직원 분들께 감사드립 니다. 끝으로 본 논문 을 사려 깊게 검토하여 주신 심사위원 님들과 편집 위원 님께 감사드립 니다.

\section{참고문헌}

Fujita, K., T. Watanabe and D. Kitagawa, 2006. Behavioral responses of the snow crab to the ground rope of a bottom trawl. Nippon Suisan Gakkaishi, 72(4), $695-701$.

Jadamec, L.S., W.E. Donaldson and P. Cullenberg, 1999.

Biological field techniques for Chionoecetes crabs. University of Alaska Sea Grant College Program, pp. 77.
Lim, Y.S., J.H. Lee, J.K. Lee, B.K. Lee, S.B. Hur, 2000. Morphometric characteristics and gonad maturity of snow crab, Chionoecetes opilio in the eastern coast of Korea. Journal of Aquaculture, 13(3), 245 - 251.

National Fisheries Research \& Development Institute (NFRDI), 2005. Stock assessment and fishery evaluation report of year 2006 TAC-based fisheries management in the adjacent Korean waters. Stock assessment and fishery evaluation, Vol. 10, 153 175.

Park, C.D., H.C. An, S.K. Cho, C.I. baik, 2003. Size selectivity of gill net for male snow crab, Chionoecetes opilio. Bull. Korean Soc. Fish. Tech., 39(2), $143-151$.

Watanabe, T. and T. Hirose, 2001. Estimation of the snow crab population density using the deep-sea video monitoring system on a towed sledge. Nippon Suisan Gakkaishi, 67(4), 640 - 646.

2008 년 10 월 29 일 접수

2009년 6월 22 일 1 차 수정

2009 년 7 월 20 일 2 차 수정

2009년 7월 30 일 수리 